\title{
Comparison of Glasgow Coma Scale, Full Outline of Unresponsiveness and Acute Physiology and Chronic Health Evaluation in Prediction of Mortality Rate Among Patients With Traumatic Brain Injury Admitted to Intensive Care Unit
}

\author{
Seyed Hossein Hosseini, ${ }^{1}$ Mitra Ayyasi, ${ }^{1}$ Hooshang Akbari, ${ }^{1}$ and Mohammad Ali Heidari Gorji $1{ }^{1}$ \\ ${ }^{1}$ Department of Nursing and Midwifery, Mazandaran University of Medical Sciences, Sari, Iran \\ "Corresponding author: Mohammad Ali Heidari Gorji, Department of Nursing and Midwifery, Mazandaran University of Medical Sciences, Sari, Iran. Tel: +98-9216298273, \\ E-mail: gorjim29@yahoo.com
}

Received 2015 October 08; Revised 2015 December 05; Accepted 2016 January 04.

\begin{abstract}
Background: Traumatic brain injury (TBI) is a common cause of mortality and disability worldwide. Choosing an appropriate diagnostic tool is critical in early stage for appropriate decision about primary diagnosis, medical care and prognosis.

objectives: This study aimed to compare the Glasgow coma scale (GCS), full outline of unresponsiveness (FOUR) and acute physiology and chronic health evaluation (APACHE II) with respect to prediction of the mortality rate of patients with TBI admitted to intensive care unit.

Patients and Methods: This diagnostic study was conducted on 80 patients with TBI in educational hospitals. The scores of APACHE II, GCS and FOUR were recorded during the first 24 hours of admission of patients. In this study, early mortality means the patient death before 14 days and delayed mortality means the patient death 15 days after admitting to hospital. The collected data were analyzed using descriptive and inductive statistics.

Results: The results showed that the mean age of the patients was $33.80 \pm 12.60$. From a total of 80 patients with TBI, 16 (20\%) were females and 64 (80\%) males. The mortality rate was 15 (18.7\%). The results showed no significant difference among three tools. In prediction of early mortality, the areas under the curve (AUCs) were $0.92(\mathrm{CI}=0.95 .0 .81-0.97), 0.90(\mathrm{CI}=0.95 .0 .74-0.94)$, and 0.96 $(\mathrm{CI}=0.95 .0 .87-0.9)$ for FOUR, APACHE II and GCS, respectively. In delayed mortality, the AUCs were $0.89(\mathrm{CI}=0.95 .0 .81-0.94), 0.94$ $(\mathrm{CI}=0.95 .0 .74-0.97)$ and $0.90(\mathrm{CI}=0.95 .0 .87-0.95)$ for FOUR, APACHE II and GCS, respectively.

Conclusions: Considering that GCS is easy to use and the FOUR can diagnose a locking syndrome along same values of subscales. These two subscales are superior to APACHI II in prediction of early mortality. Conversation APACHE II is more punctual in the prediction of delayed mortality.
\end{abstract}

Keywords: Traumatic Brain Injury, APPACHE II, FOUR, GCS, ICU

\section{Background}

Traumatic brain injury(TBI) is one of the serious causes of mortality and disability worldwide, and it is estimated that annually about 1.5 million people die and millions of them need to emergency care because of TBI. The mortality rate after TBI depends on the intensity of injury and mechanism underlying the trauma although adverse outcomes may reach 120 percent $(1,2)$. Wide cognitive and physical disability and a high TBI-related mortality rate interested the researchers to explore the ways of diagnosis and prognosis of this problem in order to proceed for better prevention strategies $(3,4)$. Today, determination of mortality and complications among patients admitted to intensive care units (ICUs) is one of the research priorities (5). Considering the cost and limitations of beds in ICU, it is very critical to determine the status of a patient in order to accept the most urgent patients $(6,7)$. Therefore, the personnel should select the patients who need urgent critical care on time, through appropriate tools $(6,7)$. Categorization of the severity of disease helps to judge about the treatment process, according to their demands and hospital facilities $(8,9)$. Considering critical situation of TBI patients for appropriate treatment $(10,11)$, there are several existing tools to estimate the hospital's mortality rate of these patients in ICU (12). Glasgow coma scale (GCS) is the most common clinical tool for primary determination of TBI (13). Several researches have shown the efficacy of GCS in prediction of mortality and morbidity (13-16). However, GCS is an appropriate tool to determine the severity of TBI, but still includes some limitations (13-18). Therefore, other tools also designed during time, for example, 
Wijdicks et al. (19) invented a tool named full outline of unresponsiveness (FOUR) in order to overcome on the limitations of GCS. This tool provides information about brainstem reflex follow-up eye and respiratory patterns, which is ignored in GCS. The FOUR measures different stages of brain herniation and locking syndrome. In addition, FOUR can assess patients in the critical condition because it does not need verbal ability $(20,21)$. The appropriate relation of FOUR scores and outcomes was surveyed in several studies (22). In the last two decades, several researchers suggested designing more efficient tools $(23,24)$. Acute physiology and chronic health evaluation (APACHE II) is one of the suggested tools, it has been used worldwide since 1985 as a physiological parameter (25). Some studies compared APACHE with GCS and other related tools (23-26). However, the result of some researchers suggested that APACHE II is not efficient in patient's undergone neurosurgery (2327), but comparing the three tools (APACHE II, APACHE III and GCS) showed similar outcome predictions (28). In another study, comparison of GCS and APACHE II in patients with head trauma revealed GCS is better than APACHE II in prediction of outcome of head trauma; however, APACHE II is better in predicting the outcomes of other traumas (25). Glasgow coma scale was also compared with FOUR and findings indicated same efficacy (22-29).

\section{Objectives}

The present study aimed to compare the prediction of mortality rate among patients with TBI admitted to ICU.

\section{Patients and Methods}

This study was a diagnostic study. The proposal of the study was approved in ethical committee of Mazandaran University of Medical Sciences and a consent form was signed by caregivers of the patients.

\subsection{Sampling and Procedure}

The study conducted on 80 patients with TBI who suffered from the impaired consciousness level in the ICU of Mazandaran University of Medical Sciences during 2012 2013. The sample size calculated based on MedCalcR, keeping power $=90, \alpha$-level as 0.05 and $\beta$-level as 0.10 , the sample size was calculated (22). The samples were selected using the purposive sampling method with a checklist based on exclusion and inclusion criteria. The inclusion criteria included TBI, age between 16 and 65 years old $(30,31)$, and admitting to the hospital more than 24 hours. The exclusion criteria were addiction history, trauma surgery problems, coma (GCS $<7$ ), and using sedative medicines before evaluation. The checklist included demographic information, type of injury, and consciousness level according to FOUR, GCS and APACHE II, etc. The patients were evaluated by the researcher through GCS, APACHE II and FOUR in first 24 hours in order to predict delayed and early mortality. Early and delayed mortality: early mortality means the patient death before 14 days and delayed mortality means the patient death 15 days after admitting to hospital.

\subsection{Tools}

a) Glasgow coma scale is a standard tool to determine severity of impairment in TBI, which is accepted by physician and neurologists worldwide. It is comprised three subscales i.e. verbal (5 items), ocular (4 items) and motor ( 6 items) ranged between 3 and 5 (13).

b) Full outline of unresponsiveness comprised four subscales i.e. ocular, motor, brain stem reflex and breathing pattern scored between 0 and 4 and the total score is between 0 and 16. Reliability and validity of FOUR have been proved in several studies (9-33).

c) Acute physiology and chronic health evaluation II assesses blood pressure, heart rate, temperature, respiratory rate, mean arterial pressure, oxygen pressure contribution, $\mathrm{pH}$, sodium and potassium and serum creatinine, hematocrit, white blood cell count, and arterial blood and ranged between 1 and 7 . Several studies reported appropriate validity and reliability of this tool (26-28).

\subsection{Statistics}

The data were analyzed through logistic regression with the 0.95 confidence level. In order to compare the three scales in the prediction of mortality, the ROCI curve was used to show cut-off point and area under the curve (AUC). $\mathrm{P}<0.05$ was considered statistically significant. Values are expressed as mean \pm standard error.

\section{Results}

The mean age of the patients was $33.80 \pm 1.60$ and their age ranged from 16 to 60 years old. From a total of 80 patients, 16 cases (20\%) were females and 64 (80\%) were males. The admission causes were as follows: 20 cases with epidural hematoma, 10 cases with subdural, 18 cases with cerebral edema and 32 cases with brain hemorrhage (Table 1 ).

The types of injury were comprised: 42 cases of motorbike accidents, 25 cases of car accidents and 13 cases fell from a height. As it is obvious, the major cause of TBI was motorbike accident. The patients admitted because motorbike accidents were in the severe level compared to other cases. Of 80 patients, 15 (18.7\%) patients expired, 11 (13.7\%) of them expired before 14 days and 4 (5\%) after 15 
Table 1. Demographic Characteristics

\begin{tabular}{|c|c|}
\hline Variable & No. (\%) \\
\hline \multicolumn{2}{|l|}{ Gender } \\
\hline Male & $64(80)$ \\
\hline Female & $16(20)$ \\
\hline \multicolumn{2}{|l|}{ Occupation } \\
\hline Unemployed & $16(20.8)$ \\
\hline Home keeper & $10(13.2)$ \\
\hline Retired & $5(5.7)$ \\
\hline Employed & $8(9.4)$ \\
\hline Others & $41(50.9)$ \\
\hline \multicolumn{2}{|l|}{ Education } \\
\hline Illiterate & $8(9.4)$ \\
\hline Elementary & $16(20.8)$ \\
\hline High school & $32(39.6)$ \\
\hline Academic & 2430.2 \\
\hline \multicolumn{2}{|l|}{ Marital status } \\
\hline Single & $47(58.5)$ \\
\hline Married & $31(39.6)$ \\
\hline Widow & $2(19.6)$ \\
\hline
\end{tabular}

days. Results of logistic regression showed no significant relationship between age, gender and cause of admission with outcomes $(\mathrm{P}>0.05)$. A significant relationship was found between outcomes of FOUR, APACHE II and GCS. Totally, the predictive power was appropriate in outcomes of APACHE II, GCS, and FOUR. The AUC of FOUR in early mortality was $0.92(\mathrm{CI}=0.95$. $0.81-0.97)$, GCS was $0.96(\mathrm{CI}=0.95$. 0.87 - 0.990) and APACHE II was $0.92(\mathrm{CI}=0.95$. 0.81 - 0.97). In delayed mortality the AUC was $0.94(\mathrm{CI}=0.95 .0 .74$ - 0.97) for FOUR, $0.90(\mathrm{CI}=0.95 .0 .87-0.95)$ for $\mathrm{GCS}$ and $0.94(\mathrm{CI}=$ 0.95. 0.74 - 0.97) for APACHE II (Figures 1 and 2). The sensitivity of FOUR in the prediction of early mortality was 0.90 and 0.90 in cut off 4, APACHE II was 0.80 in cut off 14 and 0.75 , and GCS was 0.92 and 0.100 in cut off 4 . In terms of delayed mortality prediction, the AUCs were 0.90 and 0.80 in cut off 6 for FOUR, 0.88 and 0.75 in cut off 7 for GCS, 0.90 and 0.88 in cut off 17 for APACHE II. The values of cut off sensitivity and index with AUC presented in Tables 2 and 3.

\section{Discussion}

Subjective evaluations of clinical status of patients by individual clinicians may differ in terminology, and even this difference may appear in measurement of the severity

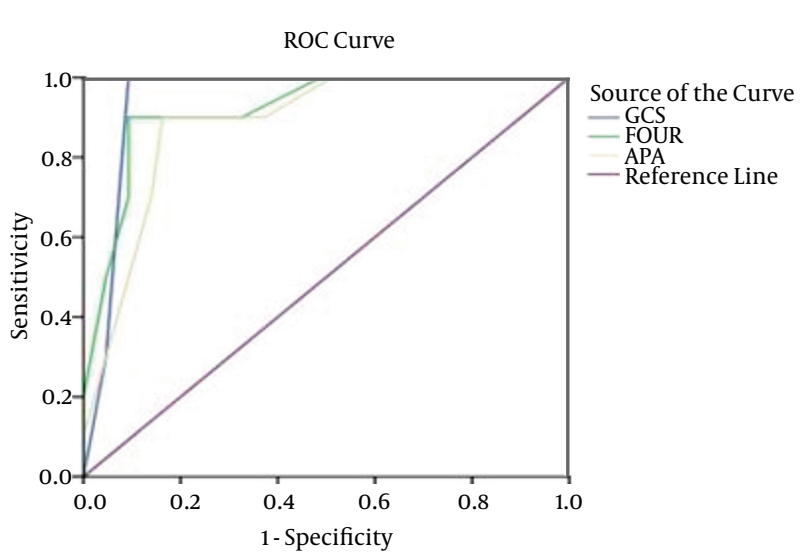

Diagonal Segments are Produced by Ties.

Figure 1. Comparison of APACHE II, GCS, and FOUR in Prediction of Early Mortality

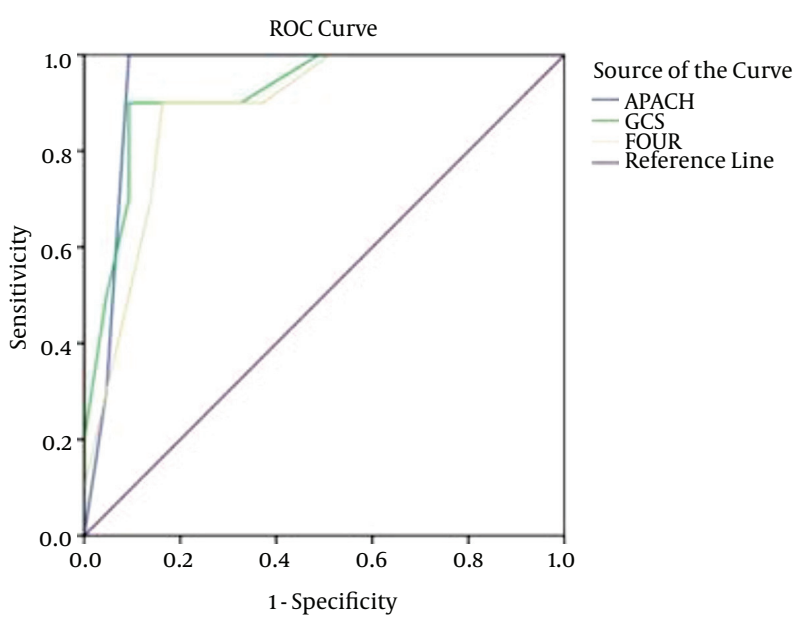

Diagonal Segments are Produced by Ties.

Figure 2. Comparison of APACHE II, GCS, and FOUR in Prediction of Delayed Mortality

of illness. Hence, several descriptive and prognostic evaluation scales have been developed during the past three decades. Objective evaluation of clinical status would facilitate comparison of methods, staff, clinical centers and studies. The need for such evaluation scales is particularly evident in coma patients (26). Therefore, this study compared GCS, FOUR and APACHE II in one study in the prediction of three tools among patients with TBI. The result showed that the majority of admitted patients were young males; this is not a surprising result as the main reason also was motorbike accident because the young males engage more frequently in risky behaviors compared to females and aged people. This result is similar to findings 
Table 2. Comparison of APACHE II, GCS, and FOUR in Prediction of Delayed Mortality

\begin{tabular}{lcccc}
\hline Score & Cut-Off Point & Specificity & Sensitivity & Youden Index \\
\hline GCS & 7 & 0.88 & 0.64 & 0.75 \\
FOUR & 6 & 0.90 & 0.73 & $0.90 \pm 0.03$ \\
APACHE II & 17 & 0.90 & 0.75 & $0.89 \pm 0.03$ \\
\hline
\end{tabular}

Abbreviations: APACHE II, acute physiology and chronic health evaluation II; GCS, glasgow coma scale; FOUR, full outline of unresponsiveness.

Table 3. Comparison of APACHE II, GCS, and FOUR in Prediction of Early Mortality

\begin{tabular}{lcccc}
\hline Score & Cut-Off Point & Specificity & Sensitivity & Youden Index \\
\hline GCS & 4 & 0.92 & 0.100 & 0.84 \\
FOUR & 4 & 0.90 & 0.90 & $0.96 \pm 0.03$ \\
APACHE II & 17 & 0.75 & 0.80 & $0.92 \pm 0.03$ \\
\hline
\end{tabular}

of other studies (22-35). In addition, results revealed that there was no relationship between age, gender, injury type and injury cause with outcomes, which is consistent with the result of a study conducted with Fakharian et al. (34). However, in a study done by Gan et al. (36) there was a significant relationship between outcome and injury mechanism and this can be due to the exclusion criteria of this study as we excluded patients above 65 years old. Furthermore, there was a significant relationship between GCS and FOUR scores with the outcomes of trauma. The prediction power was relatively similar in all three tools respectively; FOUR (AUC = 0.9), GCS (AUC = 0.96) and APACHE II $(A U C=0.90)$ in early mortality and FOUR (AUC $=0.89)$, GCS (AUC $=0.90)$ and APACHE II (AUC $=0.94)$ in delayed mortality. These findings are similar to the findings reported with Bastos et al. (37), Cho and Wang (28), Grmec and Gasparovic (26) although the mentioned studies do not included FOUR in their evaluations. In the present study, APACHE II showed better power prediction for delayed mortality and this result is explainable with characters of APACHE II which is evaluating physiologic factors, as several physical aspects are related to delayed mortality. This finding also is in accordance with the results of Cho and Wang (28). In a study conducted by Grmec and Gasparovic (26), GCS values determined before hospitalization of the patients and the APACHE II scores determined on the first day of hospitalization enabled them to compare descriptive and prognostic scales directly. They found that the prehospital GCS assessment was as good a predictor of mortality as was the APACHE II score, as measured in the hospital. On the other hand, Eken et al. (38) reported that in patients presenting with an altered level of consciousness, head trauma, or any neurological complaints on an emergency department, the FOUR-EM had a similar predic- tive value for unfavorable outcomes as the total FOUR score and the GCS. Their finding is in line with the work of Gill et al. (39) showing that the three individual GCS components alone performed similar to the total GCS score for the prediction of 4 clinically relevant TBI outcomes. Romera (40) also demonstrated that the GCS score correlates with APACHE II score in patients who have suffered a cerebrovascular accident. It was concluded that GCS is superior because of its simplicity and rapidity for prediction of mortality in patients with cerebroventricular accident. The authors of the present study also acknowledge the simplicity, rapidity and popularity of GCS regardless of the etiology of coma; however, when the situation of a patient is very sensitive and the clinician needs more information, APACHE II is more efficient in the prediction of delayed mortality. Also, FOUR has several advantages such as balance of items, diagnosis of locking syndrome, and evaluation of patients with intubation. The findings of this study revealed the relatively same efficacy in the three tools in the prediction of early mortality. However, APACHE II was more efficient in the prediction of delayed mortality, FOUR has several advantages such as balance of items, diagnosis of locking syndrome, and evaluation of patients with intubation and GCS was a simple and short tool to use. Therefore, the authors suggested that physician and nurse investigate patients' conditions with each tool considering the advantage and disadvantage of tools in the routine examination of TBI patients in the same time. The complementary information of FOUR and APACHE II beside GCS can give some critical information and insights, especially about complicated cases. Glasgow coma scale and FOUR are better to use in the first 24 hours and APACHE II is more efficient in the next stages to predict the delayed mortality. 


\section{Acknowledgments}

This study was approved by Mazadnaran University of Medical Sciences. The code and ethical approval was 51561910717008/2013.8.23. The authors would like to thank Ali Davanlu who helped us, also the ethical committee and staff and patients of the hospital.

\section{Footnote}

Authors' Contribution: Mohammad Ali Heidari Gorji supervised the procedure and edited and submitted the manuscript; Seyed Hossein Hosseini gave the idea and drafted the manuscript; Mitra Ayyasi designed the study, collected data and analyzed the data; Hooshang Akbari helped during data collection and writing procedure.

\section{References}

1. Bruns J, Hauser W. The epidemiology of traumatic brain injury. Epilepsia. 2003;44(Suply-10):2-10. [PubMed: 14511388].

2. Fleminger $\mathrm{S}$, Ponsford J. Long term outcome after traumatic brain injury. Brit Med J. 2005;331(7530):1419-20. doi: 10.1136/bmj.331.7530.1419. [PubMed: 16356951].

3. Bosman RJ, de Jonge E, de Keizer NF, Joore JC, van der Voort PH, Scheffer GJ. [Intensive care medicine in the Netherlands, 1997-2001. II. Changes over time and differences between hospitals]. Ned Tijdschr Geneeskd. 2003;147(21):1018-24. [PubMed: 12811974].

4. Pappone C, Rosanio S, Augello G, Gallus G, Vicedomini G, Mazzone $\mathrm{P}$, et al. Mortality, morbidity, and quality of life after circumferential pulmonary vein ablation for atrial fibrillation: outcomes from a controlled nonrandomized long-term study.J Am Coll Cardiol. 2003;42(2):185-97. [PubMed: 12875749].

5. Noorizad S, Tabesh H, Mahdian M, Akbari H, Taghadomi M. Causes of Mortality and Morbidity in a Neurosurgery ICU in Kashan 1999-2001. Feyz. 2005;9(2):15-20.

6. Asgari MR, Hoshmand Motlagh N, Soleimani M, Ghorbani R. The effect of transcutaneous electrical nerve stimulation on the pain intensity during insertion of vascular needles in hemodialysis patients. J Crit Care Nurse. 2012;5(3):117-24.

7. Mohammadi H, Haghighi M. Survey Relationship of Mortality Rate of Hospitalized Patients in ICU with Different Degrees of APACHE II. Quilan University Med Scie J. 2006;59(15):85-90.

8. Acharya SP, Pradhan B, Marhatta MN. Application of "the Sequential Organ Failure Assessment (SOFA) score" in predicting outcome in ICU patients with SIRS. Kathmandu Univ Med J. 2007;5(4):475-83. [PubMed: 18604078].

9. Soleimani MA, Masosi R, Bahrami N, Ghorbani M. Prediction of mortality patients hospitalized in ICU with APACH I I. J Gorgan Med. 2009(32):64-9.

10. Delney KA, Frank LRG. Manegment of the multiply injured or intoxicated. 4 ed. Newyork: Mcgraw-Hill; 2000.

11. Valadka AB, Narayan RK. Emergency room manegment of the head injury patient. Newyork: Mc graw-hill; 1996.

12. Kelly A. Predictive scoring system in the intensive care unit 2010. Available from: http:www.uptodate.com/online/content/ auther,do?topickey=cc.

13. The American Association of Neurological Surgeons. . The Brain Trauma Foundation. The American Association of Neurological Surgeons. The Joint Section on Neurotrauma and Critical Care. Glasgow coma scale score. J Neurotrauma. 2000;17(6-7):563-71. [PubMed: 10937902].
14. Signorini DF, Andrews PJD, Jones PA, Wardlaw JM, Miller JD. Predicting survival using simple clinical variables: a case study in traumatic brain injury. J Neurol Neurosurg Psychiatr. 1999;66(1):20-5. [PubMed: 9886445].

15. Bahloul M, Chelly H, Ben Hmida M, Ben Hamida C, Ksibi H, Kallel H, et al. Prognosis of traumatic head injury in South Tunisia: a multivariate analysis of 437 cases.JTrauma. 2004;57(2):255-61. [PubMed: 15345970].

16. Murray GD, Teasdale GM, Braakman R, Cohadon F, Dearden M, Iannotti F, et al. The European Brain Injury Consortium survey of head injuries. Acta Neurochir. 1999;141(3):223-36. [PubMed: 10214478].

17. Mcquillan KA, Mitchell Ph. Trauma brain injury. 3 ed. Philadelphia: $\mathrm{Wb}$ sunders; 2002.

18. Andrews PJ, Sleeman DH, Statham PF, McQuatt A, Corruble V, Jones PA, et al. Predicting recovery in patients suffering from traumatic brain injury by using admission variables and physiological data: a comparison between decision tree analysis and logistic regression. J Neurosurg. 2002;97(2):326-36. doi: 10.3171/jns.2002.97.2.0326. [PubMed: 12186460].

19. Wijdicks EF, Bamlet WR, Maramattom BV, Manno EM, McClelland RL. Validation of a new coma scale: The FOUR score. Ann Neurol. 2005;58(4):585-93. doi: 10.1002/ana.20611. [PubMed: 16178024].

20. Akaripal P. Endorasment of the four score for conciuosness assesment in neurosurgical patients. Neurol Med Chir. 2009(49):565-71.

21. Khaus WA, Wagner DP, Zimmerman JE, Draper EA. Validation and mortality and lenght of stay in intensive care unit. Ann Int Med. 1993;10(118):753-61.

22. Sadaka F, Patel D, Lakshmanan R. The FOUR score predicts outcome in patients after traumatic brain injury. Neurocrit Care. 2012;16(1):95-101. [PubMed: 21845490].

23. Arabi Y, Haddad S, Goraj R, Al-Shimemeri A, Al-Malik S. Assessment of performance of four mortality prediction systems in a Saudi Arabian intensive care unit. Crit Care. 2002;6(2):166-74. [PubMed: 11983044].

24. Gupta R, Arora VK. Performance evaluation of APACHE II score for an Indian patient with respiratory problems. Indian J Med Res. 2004;119(6):273-82. [PubMed: 15243165].

25. Dalgic A, Ergungor FM, Becan T, Elhan A, Okay O, Yuksel BC. The revised Acute Physiology and Chronic Health Evaluation System (APACHE II) is more effective than the Glasgow Coma Scale for prediction of mortality in head-injured patients with systemic trauma. Ulus Travma Acil Cerrahi Derg. 2009;15(5):453-8. [PubMed: 19779985].

26. Grmec S, Gasparovic V. Comparison of APACHE II, MEES and Glasgow Coma Scale in patients with nontraumatic coma for prediction of mortality. Acute Physiology and Chronic Health Evaluation. Mainz Emergency Evaluation System. Crit Care. 2001;5(1):19-23. doi: 10.1186/cc973. [PubMed: 11178221].

27. Amini S, Safari Malekabadi M, Roudbari M. Comparison of APACHE II, adjusted APACHE II and TRISS scores in predicting mortality rate in head trauma patients admitted to ICU at Khatam-al-Anbia hospital of Zahedan. Zahedan J Res Med Scie. 2009;11(3).

28. Cho DY, Wang YC. Comparison of the APACHE III, APACHE II and Glasgow Coma Scale in acute head injury for prediction of mortality and functional outcome. Intensive Care Med. 1997;23(1):77-84. [PubMed: 9037644].

29. Akavipat P, Sookplung P, Kaewsingha P, Maunsaiyat P. Prediction of discharge outcome with the full outline of unresponsiveness (FOUR) score in neurosurgical patients. Acta Med Okayama. 2011;65(3):205-10. [PubMed: 21709719].

30. Ritchie PD, Cameron PA, Ugoni AM, Kaye AH. A study of the functional outcome and mortality in elderly patients with head injuries. JClin Neurosci. 2000;7(4):301-4. doi: 10.1054/jocn.1999.0198. [PubMed: 10938605].

31. Lieh-Lai MW, Theodorou AA, Sarnaik AP, Meert KL, Moylan PM, Canady AI. Limitations of the Glasgow Coma Scale in predicting outcome in children with traumatic brain injury. J Pediatr. 1992;120(2 Pt 1):195-9. [PubMed: 1735814]. 
32. Stead LG, Wijdicks EF, Bhagra A, Kashyap R, Bellolio MF, Nash DL, et al. Validation of a new coma scale, the FOUR score, in the emergency department. Neurocrit Care. 2009;10(1):50-4. doi:10.1007/s12028-0089145-0. [PubMed: 18807215].

33. Iyer VN, Mandrekar JN, Danielson RD, Zubkov AY, Elmer JL, Wijdicks EF. Validity of the FOUR score coma scale in the medical intensive care unit. Mayo Clin Proc. 2009;84(8):694-701. doi: 10.1016/S00256196(11)60519-3. [PubMed: 19648386].

34. Avanji FSI, Fakharian E, Alavi NM. Outcome of factors related to traumatic brain injuries among the patients hospitalized in intensive care unit. Feyz J Kashan University Med Scie. 2010;14(2).

35. Joosse P, Smit G, Arendshorst RJ, Soedarmo S, Ponsen KJ, Goslings JC. Outcome and prognostic factors of traumatic brain injury: a prospective evaluation in a Jakarta University hospital. J Clin Neurosci. 2009;16(7):925-8. doi: 10.1016/j.jocn.2008.06.014. [PubMed: 19269829].

36. Gan BK, Lim JH, Ng IH. Outcome of moderate and severe traumatic brain injury amongst the elderly in Singapore. Ann Acad Med Singapore. 2004;33(1):63-7. [PubMed:15008565].

37. Bastos PG, Sun X, Wagner DP, Wu AW, Knaus WA. Glasgow Coma Scale score in the evaluation of outcome in the intensive care unit: findings from the Acute Physiology and Chronic Health Evaluation III study. Crit Care Med. 1993;21(10):1459-65. [PubMed: 8403953].

38. Eken C, Kartal M, Bacanli A, Eray O. Comparison of the Full Outline of Unresponsiveness Score Coma Scale and the Glasgow Coma Scale in an emergency setting population. Eur J Emerg Med. 2009;16(1):29-36. doi: 10.1097/MEJ.0b013e32830346ab. [PubMed:19106717].

39. Gill M, Windemuth R, Steele R, Green SM. A comparison of the Glasgow Coma Scale score to simplified alternative scores for the prediction of traumatic brain injury outcomes. Ann Emerg Med. 2005;45(1):37-42. doi: 10.1016/j.annemergmed.2004.07.429. [PubMed 15635308].

40. Romera E. Prognosis of stroke patients admited to the ICU. Intensive Care Med. 1997(23):162. 